\title{
CONTRIBUIÇÃo PARA A CARACTERIZAÇÃO GEOLÓGICA E CLASSIFICAÇẪO GEOMECÂNICA DOS MAÇÇOS ROCHOSOS NA CIDADE DE CRATEÚS-CE.
}

\author{
Sebastião Rodrigo Cortez de Souza ${ }^{1}$ \\ Paulo Gildânio Ferreira Teixeira ${ }^{1,2}$ \\ Fábio José Bezerra de Sousa ${ }^{1,2}$
}

10.18190/1980-8208/estudosgeologicos.v29n2p95-107

${ }^{1}$ Universidade Federal do Ceará - UFC, Campus Crateús, BR-226, Km 03, Bairro Venâncios, Crateús-CE, Brasil. E-mail: rodrigo@crateus.ufc.br.

${ }^{2}$ Graduação em Engenharia de Minas - UFC, Crateús-CE.

\section{RESUMO}

O conhecimento dos maciços rochosos e terrosos em que serão implantadas obras de engenharia civil é fundamental para a elaboração de projetos coerentes dos pontos de vista técnico e econômico. Identificar a distribuição espacial dos materiais no subsolo, caracterizá-los quantos às suas propriedades e determinar o estado de tensões permite projetar obras civis mais seguras, que otimizem recursos e que gerem menos impactos ambientais. Contudo, principalmente em cidades interioranas do Estado do Ceará, um estudo tecnicamente adequado nem sempre é realizado de forma adequada e profissional. Visando amenizar essa deficiência no município de Crateús-CE, um trabalho de caracterização geomecânica foi realizado com o objetivo de mapear e classificar o contraste de estabilidade na zona urbana do município Crateús-CE. Para tal, foi utilizado o índice de qualidade de maciço (Q), detalhado nos estudos de Barton (1974). O índice Q é calculado a partir de 6 parâmetros, que são definidos através das características obtidas em diversos afloramentos rochosos distribuídos ao longo da cidade. De posse destas informações pontuais, estes dados foram inseridos em um ambiente SIG (Sistemas de Informação Geográfica) com a finalidade de se obter a interpolação das informações e assim apresentar o produto final na forma de mapas temáticos, de grande utilidade para as empresas de construção que planejem construir obras civis na zona urbana de Crateús.

Palavras chave - Classificação Geomecânica. Estabilidade. Maciços Rochosos. Índice Q.

\begin{abstract}
The knowledge of the rocky massifs and soils in which civil engineering works will be implemented is fundamental for the elaboration of coherent projects from the technical and economic points of view. Identifying the spatial distribution of materials in the subsurface, characterizing them as to their properties and determining the state of tensions allows us to design safer civil works that optimize resources and generate less environmental impacts. However, especially in inner cities, a proper study is not carried out. Aiming to solve this deficiency in the Crateús city, Ceará state, a work of geomechanical characterization was carried out with the objective of mapping and classifying the stability contrast in the urban area of the municipality of Crateús-CE. For this, we used the mass quality index (Q), detailed in Barton's studies (1974). The Q index is calculated from 6 parameters that are defined by the characteristics obtained in several rocky outcrops distributed throughout the city. With this specific information,
\end{abstract}


these data were inserted in a GIS (Geographic Information Systems) environment in order to obtain the interpolation of the information and thus present the final product in the form of forecast maps, which will be very useful for companies to build civil works in the urban area of Crateús.

Keywords - Geomechanical Classification. Stability. Rocky Massifs. Q Index.

\section{INTRODUÇÃO}

Antes da realização de qualquer obra de construção civil é de fundamental importância determinar o comportamento geomecânico das rochas e/ou solos da área de trabalho, visando a adoção do método construtivo com a melhor relação custobenefício (Price, 2009).

A maioria dos sistemas de classificação geomecânica foi desenvolvida a partir de estudos de casos da engenharia civil (Wickham et al.,1972; Bieniawski, 1973; Barton et al., 1974; Bieniawski, 1989). Os sistemas de classificação utilizados para caracterizar os maciços rochosos possuem um conjunto de propriedades identificadas por observação direta e ensaios realizados in situ e/ou em amostras de sondagens. A finalidade destas classificações é sistematizar o conjunto de elementos geotécnicos em classes, associando a essas classes um padrão de comportamento.

Os parâmetros sobre a qualidade dos maciços rochosos podem ser obtidos através de diversos sistemas de classificação geomecâmica disponíveis na literatura. Neste trabalho utilizou-se a técnica do "Q de Barton", técnica amostral simples a qual tende a classificar o tipo de maciço de interesse, baseando principalmente na quantidade e disposição de fraturas no plano de falhas os quais são encontradas em afloramentos rochosos em uma área coincidente com a zona urbana do município de Crateús.

Muitos autores utilizaram técnicas geoestatísticas similares para estimar parâmetros geomecânicos que determinam a qualidade do maciço rochoso, como por exemplo You \& Lee (2006), Choi \& Lee (2007), Choi et al. (2009), Stavropoulou et al. (2007), Exadaktylos \& Stavropoulou (2008), Kaewkongkaew et al. (2011), Oh et al. (2004) e Egaña \& Ortiz (2013). O uso dessas técnicas tem aumentado no ramo da mecânica de rochas, pois estimar dados necessários em locais de difícil acesso é o que viabiliza o desenvolvimento de obras.

Esses dados são muito relevantes no que tange ao planejamento urbano, servindo como arcabouço para a elaboração de planos diretores, cartas geotécnicas e projetos de engenharia futuros para a cidade de Crateús. Neste sentido, com o intuito de estabelecer uma maior compreensão sobre classificação e comportamento geotécnico de maciços rochosos na área urbana da cidade.

O município de Crateús está localizado na porção oeste do estado do Ceará (Fig. 1). O município vem apresentando um considerável desenvolvimento urbano na última década, sobretudo devido à instalação de um polo educacional, tanto em nível tecnológico como superior, o que vem acarretando um acelerado crescimento da construção civil. Por este motivo, este trabalho visa caracterizar e mapear o comportamento geomecânico das rochas expostas (afloramentos) na zona urbana da cidade de Crateús, com vias de nortear futuras construções civis e o melhor uso do solo na área de abrangência do estudo. 


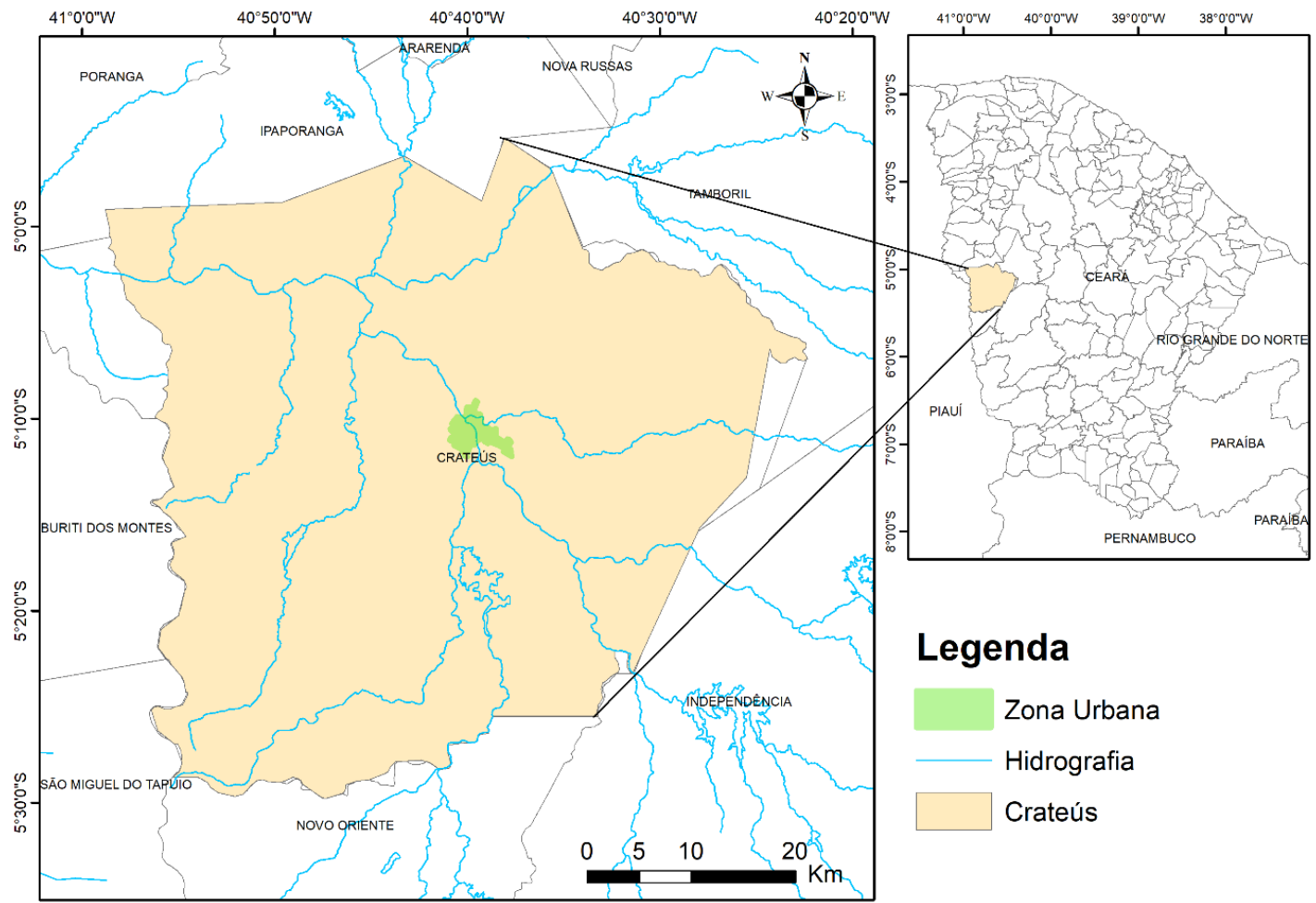

Figura 1. Localização do município de Crateús-CE e da área de estudo deste trabalho.

\section{CARACTERIZAÇÃO GEOLÓGICA DA ÁREA DE ESTUDO}

O contexto geológico regional é referente ao Domínio Ceará Central, porção norte da Província Borborema, e é bem descrito nos trabalhos de mapeamento geológico regional sistemático da CPRM (Costa, 2017), visualizados na figura 2 .

O Domínio Ceará Central é representado por um embasamento arqueano/paleoproterozóico, supracrustais meso/neoproterozóica e intensa granitogênese neoproterozóica associada ao evento Pan-Africano/Brasiliano, responsável pela colagem ocidental do super-continente Gondwana. A unidade mais antiga, provavelmente paleoproterozóica (?), refere-se ao Complexo Canindé do Ceará, mapeado como uma sequência predominantemente paraderivada, com-posta por biotita-gnaisses, migmatitos, lentes de rochas metabásicas e matacalcários.

Grande parte da área mapeada, cerca de $40 \%$, é representada por um domínio granito-migmatítico neoproterozóico denominado de Complexo Tamboril-Santa Quitéria, sendo dividido em: (1) Diatexitos representados principalmente por uma fase anatética rosa, de natureza cálcio-alcalina de alto$\mathrm{K}$, levemente peraluminosa, derivada da fusão parcial de rochas dioríticas/ tonalíticas de crosta média/inferior; (2) Granitóides, que constituem intrusões sin- a tardi-anatéticas, apresentam feições de mistura de magmas, e são representados por monzonitos, sienitos e quartzo-monzonitos, com assinatura shoshonítica e raramente ultrapotássica. Para este magmatismo híbrido é sugerida a participação de uma fonte mantélica previamente enriquecida por metassomatismo. 


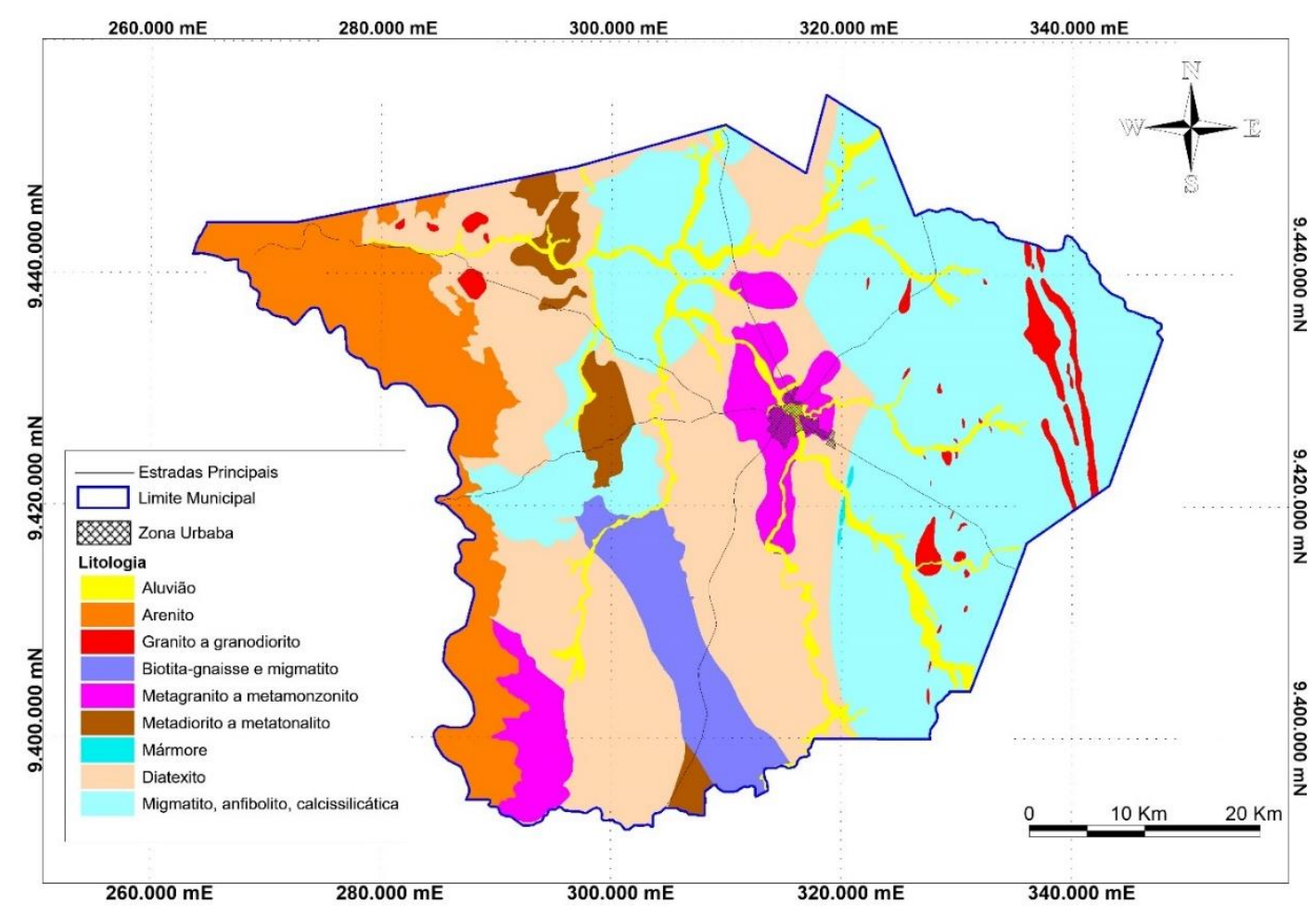

Figura 2. Mapa geológico do município de Crateús-CE, segundo dados disponibilizados pela CPRM (modificado de Costa, 2017).

As rochas aflorantes na região de estudo são em sua maioria rochas metamórficas ortoderivadas, compostas principalmente por minerais félsicos (quartzo e feldspato potássico) e subordinadamente por minerais máficos (biotita e anfibólio), as vezes recortadas por diques e stocks de rochas graníticas ácidas (Fig. 3). Localmente são encontrados milonitos produzidos em zonas de falhas como produtos de efeitos tectônicos. Essas zonas de falhas são caracterizadas por um intenso faturamento, de caráter tectônico, quase sempre hospedando drenagens devido às facilidades erosivas e por este motivo quase sempre se localizando em regiões mais baixas topograficamente. Em geral, os solos são pouco expressivos, do tipo transportados e normalmente não ultrapassam $30 \mathrm{~cm}$ de profundidade.

A figura 3 também mostra a localização dos 14 pontos amostrados para a caracterização geomecânica deste trabalho. A partir do mapa geológico de Costa (2017), foram incrementadas algumas melhorias ao resultado do mapeamento geológico na área urbana do município de Crateús (Fig. 3). 


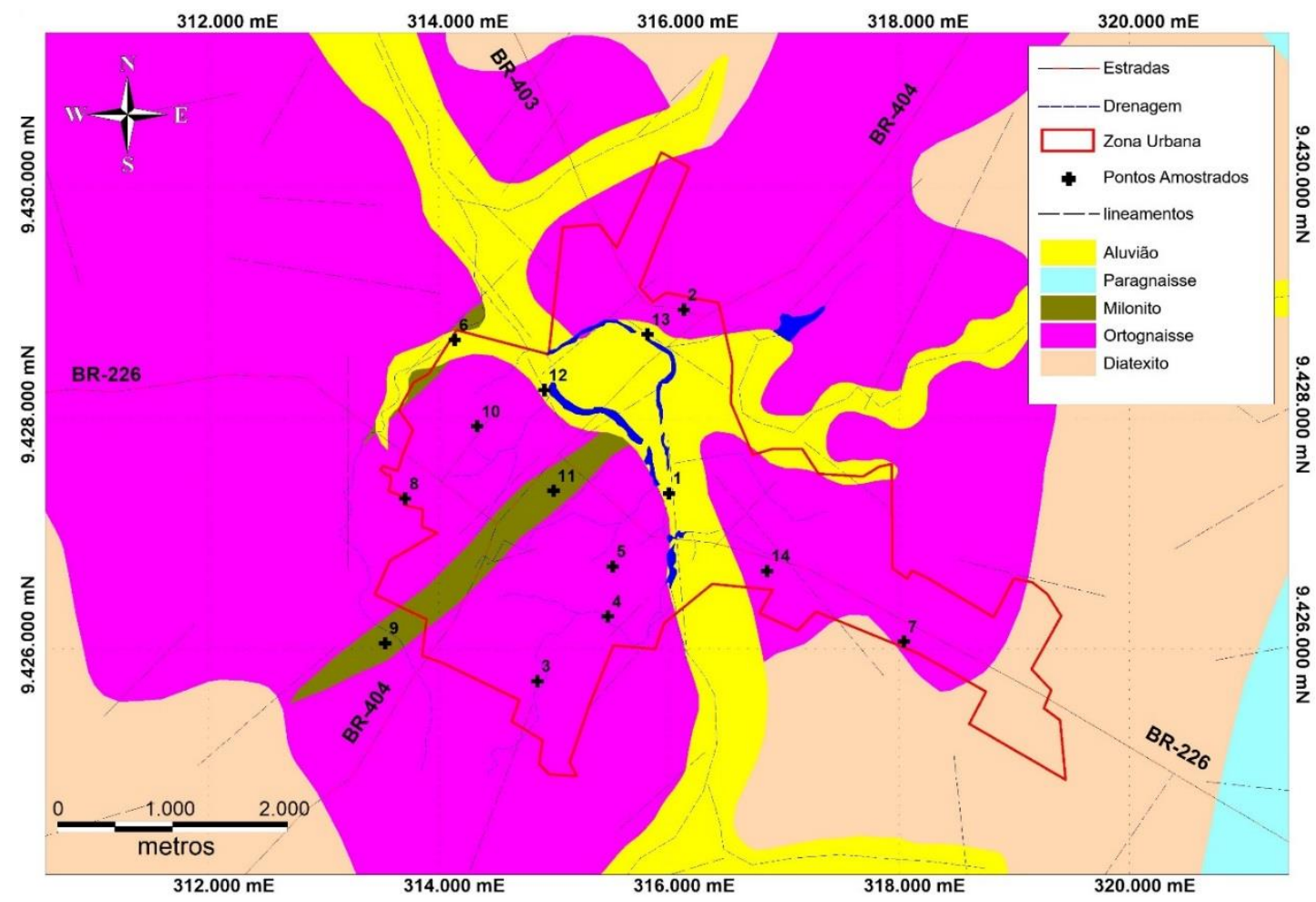

Figura 3. Mapa geológico do entorno da área urbana da cidade de Crateús-CE (modificado de Costa, 2017).

Para complementar as informações geológicas obtidas a partir do mapeamento sistemático da CPRM e do trabalho de campo, um estudo de extração dos principais lineamentos estruturais foi executado na mesma área. Este estudo foi realizado usando como base imagens do sensor remoto GeoEye $^{\circledR}$, disponibilizadas pelo aplicativo Google Earth $^{\circledR}$ e através de imagens de radar SRTM ${ }^{\circledR}$ e Jers ${ }^{\circledR}$.

No total foram extraídos 44 lineamentos estruturais, que após serem agrupados, foram classificados em 4 famílias: Lineamentos E-W (Fig. 4a), Lineamentos NE-SW (Fig. 4b), Lineamentos NW-SE (Fig. 4c) e
Lineamentos N-S (Fig. 4d). Em termos de representação espacial, os lineamentos NE-SW são os mais abrangentes, perfazendo aproximadamente $52 \%$ dos lineamentos estudados. São seguidos pelos lineamentos E-W (cerca de 20,5\%), pelos lineamentos NW-SE (cerca de $18,2 \%)$ e pelos lineamentos N-W (cerca de 9,3\%). A figura 4 sintetiza as informações dispostas acima.

Desta forma, é provável correlacionar a direção NE-SW com as principais estruturas encontradas na área, sobretudo desenvolvendo famílias de fraturas rúpteis e zonas de fraquezas no terreno. 


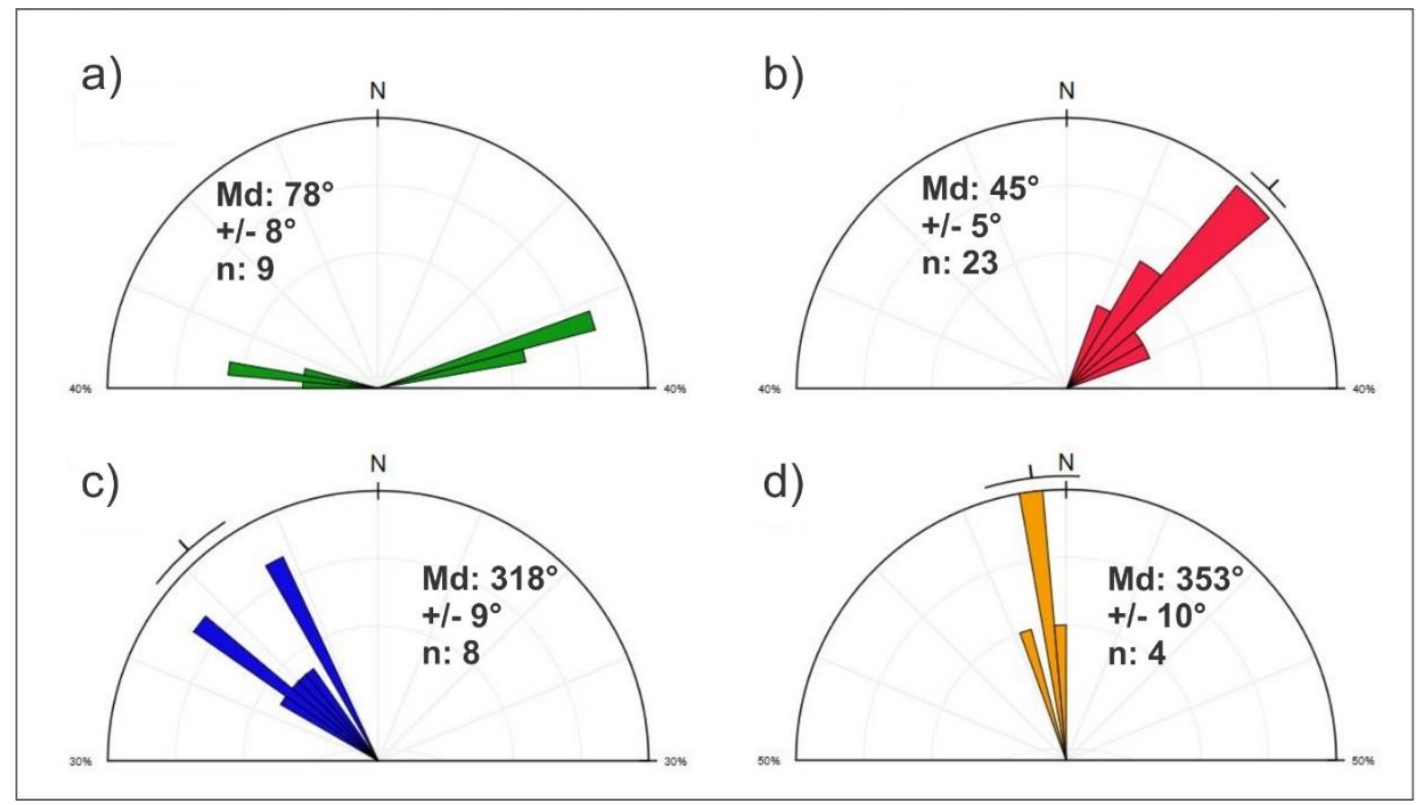

Figura 4. Distribuição dos lineamentos estruturais interpretados a partir de sensores remotos observados na área de estudo.

Foram analisados catorze (14) afloramentos rochosos distribuídos ao longo da zona urbana da cidade de Crateús (Tabela 1 e Fig. 3). Embora a quantidade de afloramentos seja relativamente pequena, têm-se que considerar o fato do estudo ser realizado em zona urbana, onde praticamente inexistem exposições rochosas, sobretudo, devido ao forte antropismo causado pela construção civil. Em cada afloramento foram coletadas informações litológicas e estruturais, bem como estimados os parâmetros para o cálculo do índice Q de Barton.

Tabela 1. Coordenadas e descrição litológica dos pontos coletados neste trabalho.

\begin{tabular}{c|ccc}
\hline \multicolumn{1}{c}{ PONTO } & LONGITUDE & LATITUDE & LITOLOGIA \\
\hline $\mathbf{1}$ & 316001 & 9427349 & Ortognaisse \\
$\mathbf{2}$ & 316131 & 9428942 & Ortognaisse \\
$\mathbf{3}$ & 314860 & 9425718 & Ortognaisse \\
$\mathbf{4}$ & 315472 & 9426278 & Ortognaisse \\
$\mathbf{5}$ & 315513 & 9426713 & Ortognaisse \\
$\mathbf{6}$ & 314142 & 9428682 & Milonito \\
$\mathbf{7}$ & 318044 & 9426061 & Ortognaisse \\
$\mathbf{8}$ & 313712 & 9427302 & Ortognaisse \\
$\mathbf{9}$ & 313538 & 9426046 & Milonito \\
$\mathbf{1 0}$ & 314337 & 9427931 & Ortognaisse \\
$\mathbf{1 1}$ & 315000 & 9427371 & Milonito \\
$\mathbf{1 2}$ & 314921 & 9428244 & Ortognaisse \\
$\mathbf{1 3}$ & 315817 & 9428730 & Ortognaisse \\
$\mathbf{1 4}$ & 316856 & 9426674 & Ortognaisse \\
\hline
\end{tabular}




\section{MATERIAL E MÉTODO}

O índice Q (Barton et al., 1974) é definido através de 6 parâmetros calculados utilizando-se a macro Excel $^{\circledR} \quad$ (Fig. 5), e classificados conforme a Tabela 2:

- $\quad$ RQD é o índice de qualidade da rocha e indica a porcentagem de rocha recuperada em intervalos de rocha intactos iguais ou maiores que $10 \mathrm{~cm}$ em um afloramento de $2 \mathrm{~m}$ de comprimento.

- $\quad \underline{\mathrm{Jn}}$ é caracterizado pelo resultado do mapeamento $\mathrm{e}$ agrupamento de famílias de fraturas.
- $\quad \underline{\mathrm{Jr}}$ é o determinante das condições de rugosidade ou textura das superfícies principais, definindo sua escala, menor ou maior.

- $\quad \underline{J a}$ descreve as condições de alteração e fricção das fraturas.

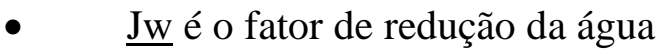
e mede o efeito da fraqueza de alterações sob estas condições.

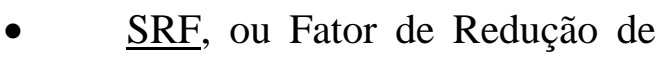
Estresse (Stress Reduction Factor), que dimensiona o fraturamento da rocha devido ao excesso de estresse.

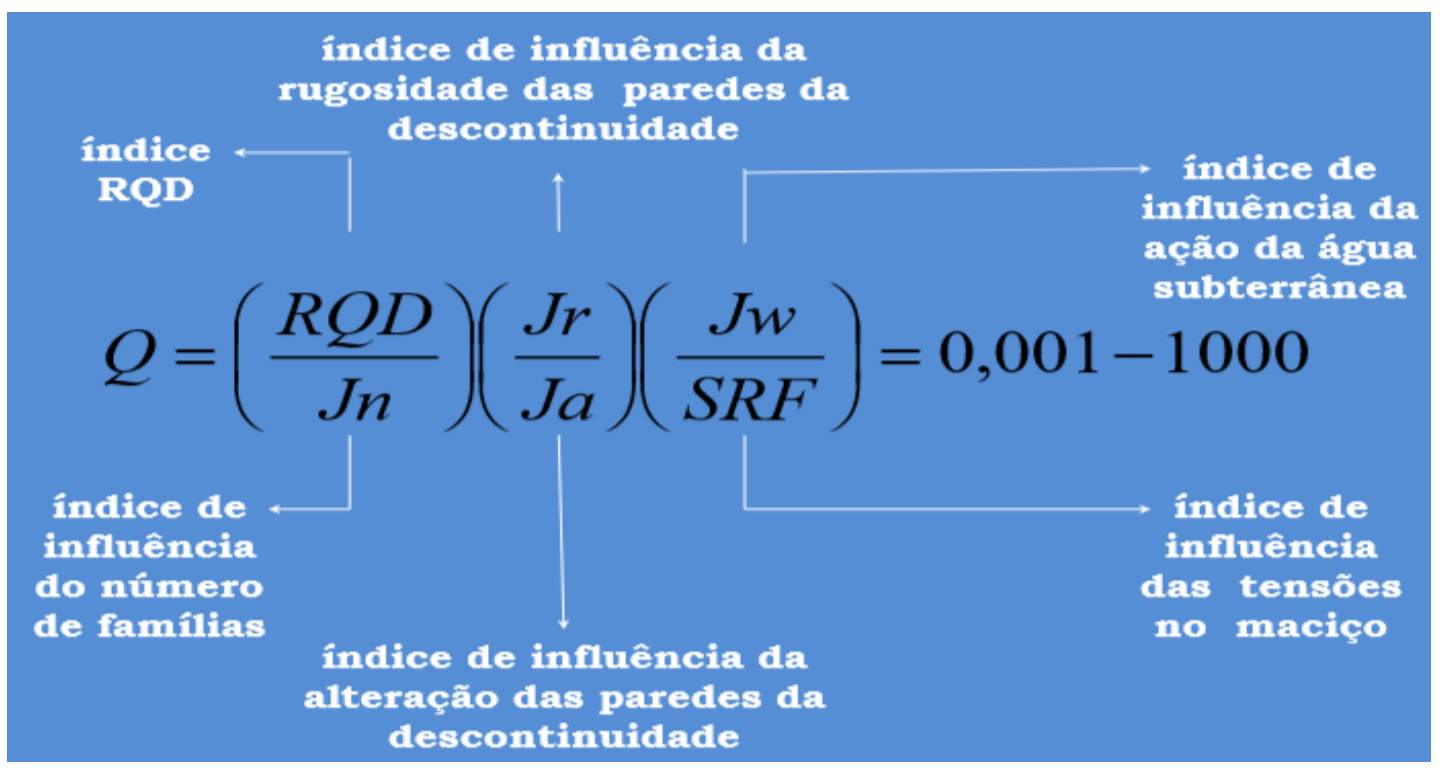

Figura 5. Composição e parâmetros utilizados para a composição do índice Q de Barton.

Tabela 2. Classificação do maciço rochoso segundo os valores de Q de Barton.

\begin{tabular}{c|c}
\hline Valor do Índice de Barton & Classificação do Maciço \\
\hline $0,001-0,01$ & Excepcionalmente Pobre \\
$0,01-0,1$ & Extremamente Pobre \\
$0,1-1$ & Muito Pobre \\
$1-4$ & Pobre \\
$4-10$ & Regular \\
$10-40$ & Bom \\
$40-100$ & Muito Bom \\
$100-400$ & Extremamente Bom \\
$400-1000$ & Excepcionalmente Bom \\
\hline
\end{tabular}

Estudos Geológicos vol 29(2)

https://periodicos.ufpe.br/revistas/estudosgeologicos 
Em cada afloramento, foram coletadas informações estruturais, tais como direção, espessura e classificação das famílias de fraturas existentes, bem como a litologia associada.

Por fim, após a determinação do valor de $Q$ de Barton para cada afloramento, foi criado um mapa de interpolação estatística com a ajuda do software MapInfo Professional $12^{\circledR}$ (módulo Encom Discover $15^{\circledR}$ ) abrangendo toda a área de estudo, usando método do inverso do quadrado da distância, com os seguintes parâmetros:

- Inverse Distance Weighting

- 49 columns, 25 rows

- Cell size: 0,002
- Search distance: 0,02

- Nearest neighbors: min. 1 and max 9.

\section{RESULTADOS}

Os resultados de $\mathrm{Q}$ de Barton foram calculados para catorze (14) afloramentos estudados na cidade de Crateús e podem ser vistos na Tabela 3. A propósito de a malha amostral apresentar irregularidades na sua configuração, é valido salientar que o estudo foi realizado na zona urbana do município, e assim sendo, na maioria das vezes inexistem afloramentos que possam ser estudados para efeitos deste trabalho.

Tabela 3. Parâmetros amostrados e valores obtidos para os pontos coletados neste trabalho.

\begin{tabular}{|c|c|c|c|c|c|c|c|c|c|c|}
\hline \multirow[t]{2}{*}{ PONTO } & \multicolumn{6}{|c|}{$\begin{array}{l}\text { PARÂMETROS OBTIDOS EM } \\
\text { CAMPO }\end{array}$} & \multicolumn{4}{|c|}{ PARÂMETROS CALCULADOS } \\
\hline & RQD & Jn & $\mathbf{J r}$ & $\mathbf{J a}$ & $\mathbf{J w}$ & SRF & RQD/Jn & $\mathbf{J r} / \mathbf{J a}$ & Jw/SRF & $\begin{array}{c}\text { Q } \\
\text { BARTON }\end{array}$ \\
\hline 1 & 96,35 & 3,00 & 4,00 & 1,00 & 1,00 & 0,50 & 32,12 & 4,00 & 2,00 & 256,93 \\
\hline 2 & 92,73 & 3,00 & 4,00 & 1,00 & 1,00 & 0,50 & 30,91 & 4,00 & 2,00 & 247,28 \\
\hline 3 & 94,85 & 3,00 & 3,00 & 1,00 & 1,00 & 0,40 & 31,62 & 3,00 & 2,50 & 237,13 \\
\hline 4 & 86,65 & 6,00 & 3,00 & 1,00 & 1,00 & 0,50 & 14,44 & 3,00 & 2,00 & 86,65 \\
\hline 5 & 97,50 & 3,00 & 3,00 & 1,00 & 1,00 & 0,40 & 32,50 & 3,00 & 2,50 & 243,75 \\
\hline 6 & 80,75 & 6,00 & 3,00 & 1,00 & 1,00 & 0,50 & 13,46 & 3,00 & 2,00 & 80,75 \\
\hline 7 & 96,25 & 3,00 & 3,00 & 1,00 & 1,00 & 0,50 & 32,08 & 3,00 & 2,00 & 192,49 \\
\hline 8 & 93,45 & 3,00 & 4,00 & 1,00 & 1,00 & 0,50 & 31,15 & 4,00 & 2,00 & 249,20 \\
\hline 9 & 86,91 & 6,00 & 3,00 & 1,00 & 1,00 & 0,50 & 14,49 & 3,00 & 2,00 & 86,91 \\
\hline 10 & 94,00 & 3,00 & 3,00 & 1,00 & 1,00 & 0,40 & 31,33 & 3,00 & 2,50 & 235,00 \\
\hline 11 & 88,35 & 6,00 & 3,00 & 1,00 & 1,00 & 0,50 & 14,73 & 3,00 & 2,00 & 88,35 \\
\hline 12 & 98,10 & 3,00 & 4,00 & 1,00 & 1,00 & 0,50 & 32,70 & 4,00 & 2,00 & 261,60 \\
\hline 13 & 95,30 & 3,00 & 3,00 & 1,00 & 1,00 & 0,50 & 31,77 & 3,00 & 2,00 & 190,60 \\
\hline 14 & 96,05 & 3,00 & 4,00 & 1,00 & 1,00 & 0,50 & 32,02 & 4,00 & 2,00 & 256,13 \\
\hline
\end{tabular}


Segundo Barton et.al. (1974), os valores de $Q$ variam de 0,001 (excepcionalmente pobres) a 1000 (excepcionalmente bons) (Tabela 2). Dentre os valores obtidos neste trabalho, dez (10) pontos $(1,2,3,5,7,8,10,12$, 13 e 14) estão inseridos entre a categoria de valores de 100 a 400, o que permite classificá-los como sendo valores extremamente bons para o índice Q. Entretanto, quatro (04) pontos (4, 6, 9 e 11) estão localizados na categoria de valores entre 40 a 100 (valores muito bons).
Em cada ponto de afloramento estudo, as informações estruturais e litológicas foram complementadas com fotografias e um croqui esquemático, onde são destacadas as falhas/fraturas observadas em campo, em escala adequada. Como exemplificação do exposto acima, a figura 6 mostra o ponto do afloramento 12 (RQD=98,10 e $\mathrm{Q}=261,60)$. $\mathrm{Na}$ figura $6 \mathrm{a}$ tem-se a fotografia representativa do afloramento, e na figura $6 \mathrm{~b}$ tem-se o croqui do mesmo, com destaque para as intercessões das fraturas ao longo do intervalo amostrado no estudo.
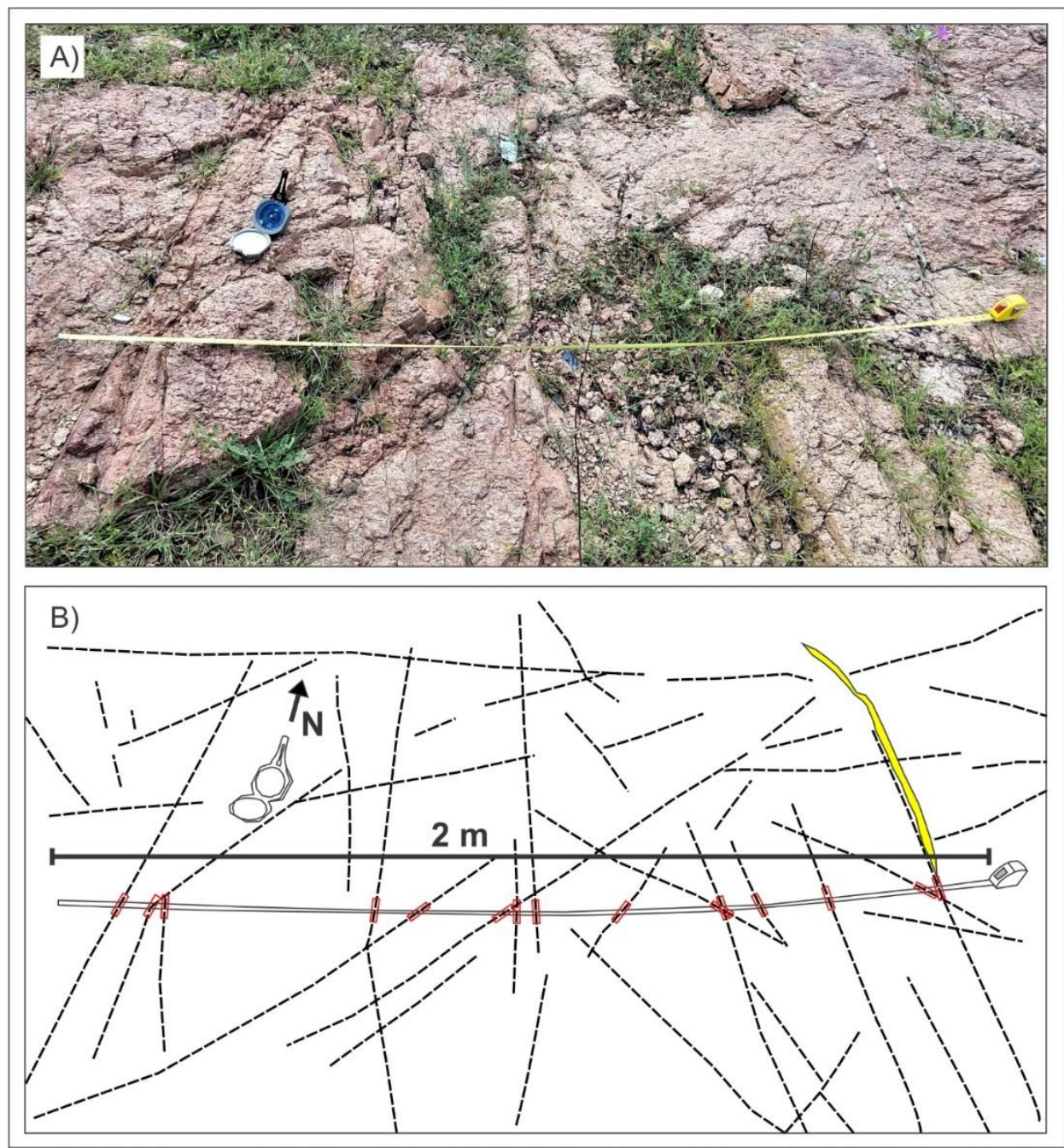

Figura 6. A) Fotografia representativa do afloramento 12. B) Croqui de A, com destaque para as intercessões das fraturas ao longo do intervalo amostrado no estudo (em vermelho). Afloramento em piso. 
Avaliando-se a resposta reológica das zonas rúpteis de cada afloramento, na forma de diagramas de rosetas individuais, pode-se notar que existe uma heterogeneidade na variação de resultados ao longo dos 14 pontos estudados em campo. A figura 7 mostra os resultados obtidos, para cada ponto. Apesar dos resultados pouco homogêneos, pode-se destacar que em geral o grupo de famílias de fraturas que mais se destacam são as de direção NE-SW, seguidos pelas famílias de fraturas E-W, corroborando o resultado obtido a partir do estudo de lineamentos interpretados sob sensores remotos, demonstrando a validade desta técnica.

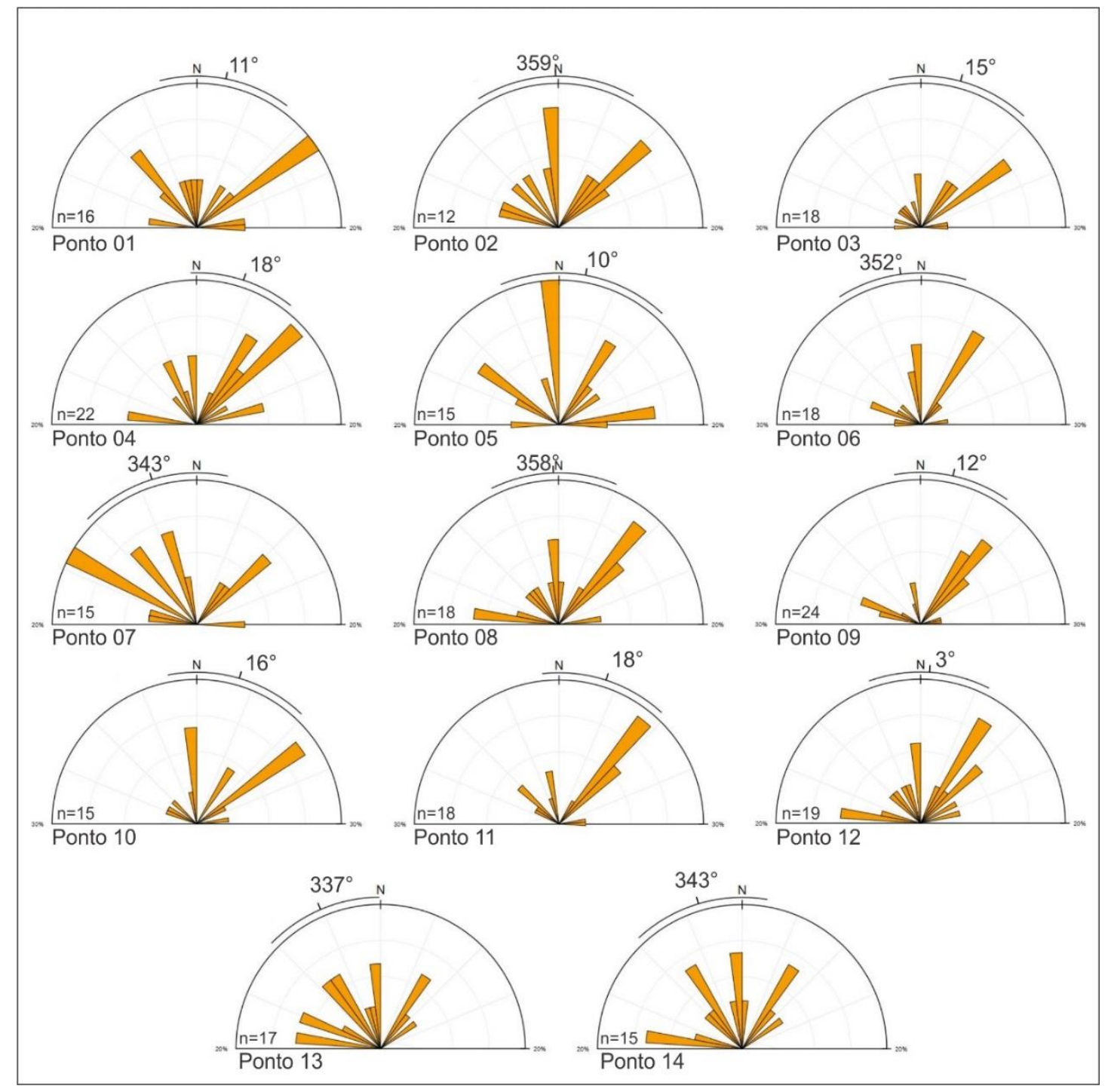

Figura 7. Direção preferencial das famílias de fraturas observadas em cada um dos pontos de estudo.

\section{DISCUSSÃO}

O processamento geoestatístico para estimar os parâmetros geomecânicos de $\mathrm{Q}$ de Barton para a área urbana do município de Crateús-CE resultou no mapa exposto na figura 8. Este mapa determina a qualidade do maciço e fornece uma boa indicação para a capacidade de resistência mecânica do substrato rochoso ante a execução de projetos de construção 
civil, com a finalidade de indicar a previsionabilidade da distribuição dos valores de $\mathrm{Q}$ ao longo da zona urbana do município de Crateús.

É possível notar que de uma forma geral os valores de $\mathrm{Q}$ de Barton são consideravelmente altos na zona urbana da cidade de Crateus-CE, indicando pouco faturamento e uma constituição geológica favorável à resistência do maciço rochoso (Fig. 8). Entretanto, alguns pontos com valores de Q abaixo de 100 foram reportados (pontos 4, 6, 9 e 11), quase sempre associados a zonas de falhas, em corredores de cisalhamento, onde afloram rochas milonitizadas com forte presença de água percolando microfraturas. Dentre essas áreas, destaca-se a área compreendida pelo ponto $11(\mathrm{Q}=88,35)$, que se localiza no centro da cidade, em uma área com forte estímulo à verticalização futura. As regiões dos ponto $4(\mathrm{Q}=86,65), 6(\mathrm{Q}=80,75)$ e $9(\mathrm{Q}=86,91)$, apesar do valores $Q$ baixos, despertam menos atenção à riscos construtivos e/ou de resistência estrutural devido a estarem localizadas em zonas periféricas, com baixa taxa de urbanização e pouca atratividade para grandes projetos futuros de construção civil pesada.

Conforme já mencionado anteriormente, o mapeamento apresenta algumas heterogeneidades amostrais que certamente afetariam a interpolação geoestatística realizada.

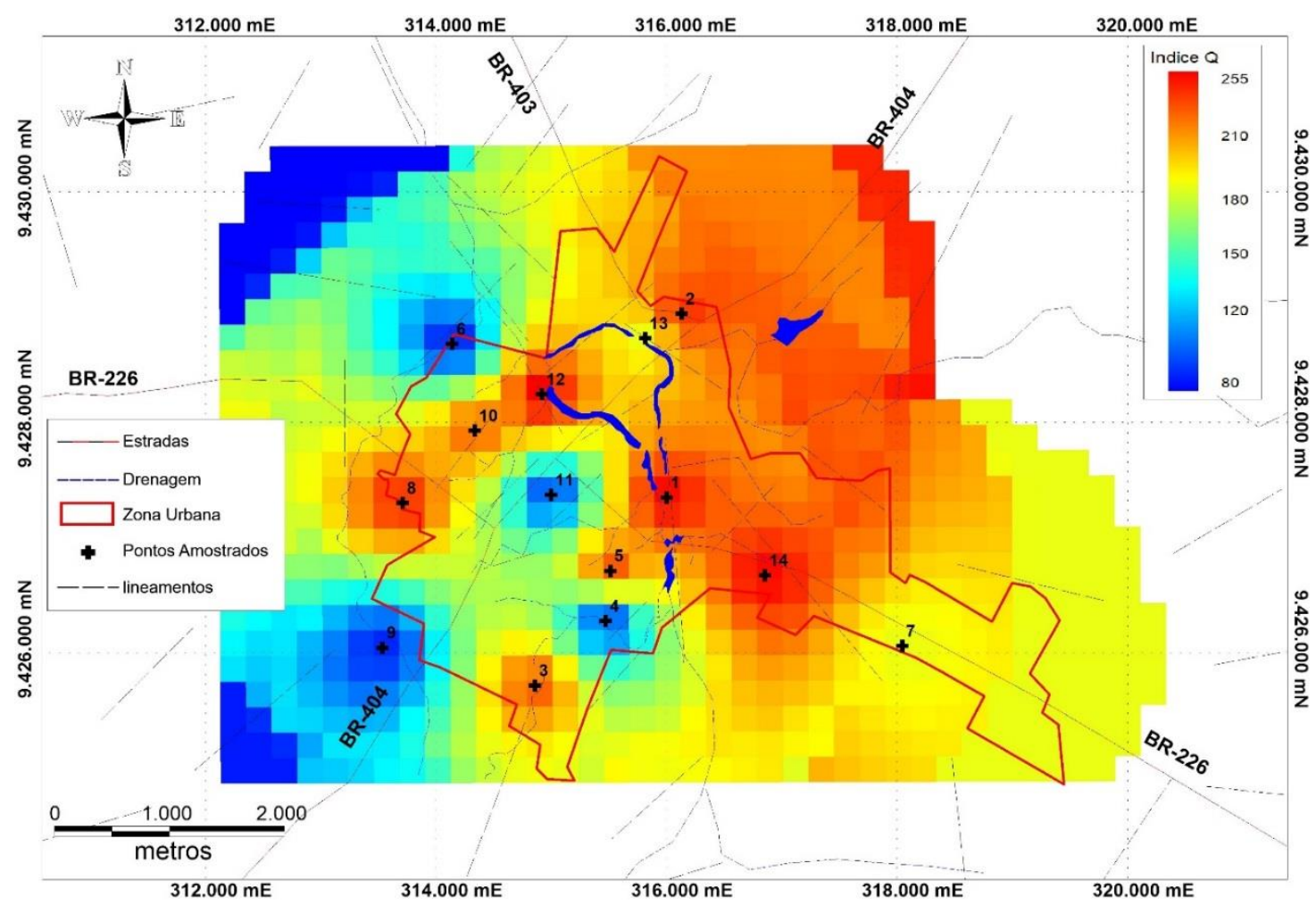

Figura 8. Mapa de interpolação geoestatística dos valores de Q de Barton obtidos neste trabalho.

Entretanto, cabe ressaltar que uma amostragem regular não foi possível devido à falta de afloramentos na zona urbana da cidade de Crateús.

\section{CONCLUSÕES}

Um trabalho de levantamento de informações geológicas, estruturais e geomecânicas foi realizado ao longo de 
catorze afloramentos que representam a região de zona urbana do município de Crateús-CE. As principais rochas que afloram no município são metamórficas ortoderivadas, em geral fracamente fraturadas, compostas predominantemente por minerais félsicos resistentes à maioria das condições mecânicas. $\mathrm{O}$ índice $Q$ de Barton foi calculado para cada um dos catorze afloramentos, e seus valores foram interpolados estatisticamente para ser possível gerar um mapa de previsão para valores ao longo da zona urbana do município. Este estudo comprovou que os valores de $\mathrm{Q}$ obtidos são consistentemente altos, classificados como muito bom $(80,75$ a 88,35$)$ a extremamente bom $(192,49$ a 256,93$)$, o que comprova que a região está situada sobre um embasamento geológico que funciona como um substrato de alta favorabilidade para a execução de obras civis de uma forma em geral, caracterizado por uma excelente resistência mecânica e muito boas caracterizações geomecânicas.

\section{REFERÊNCIAS}

Barton, N., Lien, R., Lunde, J. 1974. Engineering classification of rock masses for the design of tunnel support. Rock Mechanics. V.6, n.4, p. 189-236.

Bieniawski, Z. T. 1989. Engineering Rock Mass Classification, New York: John Wiley \& Sons. 251 p.

Bieniawski, Z. T. 1973. Engineering Classification of Jointed Rock Masses, Trans. S. Afr. Inst. Civ. Eng., 15, pp. 335-344.

Choi, J. Y., Lee, C. I. 2007. An estimation of rock mass rating using 3D-indicator kriging approach with uncertainty assessment of rock mass classification. Proceeding of the 11th congress of the International
Society for Rock Mechanics. Lisbon, 2, pp. 285-288.

Choi, Y., Yoon, S.Y., Park, H.D. 2009. Tunnelling Analyst: A 3D GIS extension for rock mass classification and fault zone analysis in tunnelling. Computers \& Geosciences, 35, pp. 1322-1333.

Costa, F. G. (Org). 2017. Geologia e recursos minerais da folha Crateús - SB.24-V-C-III: estados do Ceará e Piauí. Escala 1:100.000. Fortaleza: CPRM. 117p.

Egaña, M., Ortiz, J.M. 2013. Assessment of RMR and its uncertainty by using geostatistical simulation in a mining project. Journal of GeoEngineering, 8 (3), pp. 83-90.

Exadaktylos, G., Stravopoulou, M., Xiroudakis, G., De Broissia, M., Schwarz, H. 2008. A spatial estimation model for continuous rock mass characterization from the specific energy of a TBM. Rock Mechanics and Rock Engineering, 41, pp. 797-834.

Kaewkongkaew, K., Phien, N., Harnpattanapanich, T., Sutiwanich, C. 2011. Geological Model of Mae Tang-Mae Ngad Diversion Tunnel Project, Northern Thailand. Open Journal of Geology, 3 (5), pp. 340-351.

Oh, S., Chung, H., Lee, D. K. 2004. Geostatistical integration of MT and borehole data for RMR evaluation. Enviromental Geology, 46, pp. 1070-1078.

Price, D. G. 2009. Engineering Geology: Principles and Practice. SpringerVerlag. Berlin. 460p.

Stavropoulou, M., Exadaktylos, G., Saratsis, G. 2007. A Combined Three-Dimensional GeologicalGeostatistical-Numerical Model of Underground Excavations in Rock. Rock Mechanics and Rock Engineering, 40 (3), pp. 213-243. 
Wickham, G.E., Tiedemann, H.R., Skinenr, E.H. 1972. Support determination based on geologic predictions. Proc. North American rapid excav. tunneling conf, pp. 43-64.

You, K., Lee, J.S. 2006. Estimation of Rock Mass Classes using the 3
Dimensional Multiple Indicator Kriging Technique. Tunnelling and Underground Space Technology incorporating Trenchless Technology Research, 21 (3/4), pp. 229-234. 